SHORT REPORT

\title{
The "Lasso-o" tape: stretchability and observer variability in head circumference measurement
}

\author{
J L Bartram, A S Rigby, P S Baxter
}

Arch Dis Child 2005;90:820-821. doi: 10.1136/adc.2004.063743

Head circumference is an important clinical measurement in children. The stretchability of the Lasso-o tape and the intraand inter-observer reproducibility of measurements using it were investigated. Old Lasso-o tapes stretch significantly. The intra-class coefficients were 0.999 for intra-observer and 0.979 for inter-observer measurements. Nonetheless in $9 \%$ of measurements inter-observer variability was over $1 \mathrm{~cm}$.

$M$ easurement of head circumference (occipito-frontal circumference) is a routine part of the physical examination of a child and is of great importance in detecting abnormal patterns of growth. Clinical decisions can depend on serial changes in the measurement. Head circumference is also widely used as a variable in research. Apart from studies in neonates, ${ }^{1}$ few studies have examined the accuracy of measurement. In recent years in the UK the Lasso-o tape has been marketed specifically for head circumference measurement. Anecdotal evidence from clinics and ward rounds highlighted that older Lasso-o tapes, some of which were in bad condition, appeared to be of different lengths and were more easily stretched. Currently there are no guidelines on when to replace the tapes. We therefore wished to assess whether the Lasso-o tape is still an accurate measuring tool after multiple use and to apply measures of intra- and inter-observer variability and reproducibility of head circumference measurement using the Lasso-o tape.

\section{METHODS}

Tapes were tested at the University of Sheffield Department of Engineering, under standard conditions of constant temperature and humidity. The normal range of force required in clinical practice was calculated using Newton meters attached to a tape wrapped around a volunteer's head. Varying continuous tensile forces were then applied to four new and six old Lasso-o tapes from clinics and wards, to simulate multiple strain-relax forces. Their change in lengths were measured against a calibrated steel rule and compared by paired one tailed $t$ tests.

Ethical approval was obtained from South Sheffield Local Research Ethics Committee.

Using new Lasso-o tapes the head circumferences of 79 outpatients aged 3 weeks to 16 years were measured by three observers, blinded to each other's results, to assess interobserver differences. One observer made repeated measurements to assess intra-observer reliability. The differences between readings, and their correlation and agreement were analysed using the Pearson correlation coefficient and the intra-class correlation coefficient. The latter reflects the difference in mean values as well as the degree of correlation between the two sets. Inter-observer measurements were also compared by analysis of the variance, as this is the only method which directly compares all three: an F value greater than or equal to $\mathrm{F}$ critical indicates a significant difference. ${ }^{2-4}$

\section{RESULTS}

In the clinical force range (fig 1), the length of new Lasso-o tapes increased from a mean of 70.0 to $70.2 \mathrm{~cm}$ (95\% CI 0.0 to $0.3 ; p=0.28)$. Old tapes increased from a mean of 70.1 to $70.6 \mathrm{~cm}(95 \%$ CI 0.3 to $0.7 ; \mathrm{p}=0.02)$.

\section{Intra-observer measurements}

The Pearson correlation coefficient was 0.996 and the intraclass correlation coefficient 0.999 . The limits of agreement were -0.71 to $0.65 \mathrm{~cm}$, which indicates that $5 \%$ of measurements differed by $0.65 \mathrm{~cm}$ or more. Standard error of measurement was $0.24 \mathrm{~cm}$, with repeatability of $\pm 0.66 \mathrm{~cm}$ and relative bias of $\pm 0.47 \mathrm{~cm}$, which means that in statistical terms $95 \%$ of the time when the observer takes two measurements they will be within $0.66 \mathrm{~cm}$ of each other and within $0.47 \mathrm{~cm}$ of the underlying "true" value. The mean difference between measurements was $0.26 \mathrm{~cm}$.

\section{Inter-observer measurements}

Pearson's correlation matrix and a mean difference matrix showed good overall agreement between observers. Intraclass correlation coefficient was 0.979. Analysis of the variance gave an $\mathrm{F}$ value $=0.574$ with $\mathrm{F}$ critical $=3.05 \mathrm{l}$, which shows no significant difference. In seven patients (9\%) the difference was greater than $1 \mathrm{~cm}$.

\section{DISCUSSION}

We found that with forces used in clinical practice Lasso-o tapes stretch significantly and that this increases after multiple use. For new tapes this is statistically but probably not clinically significant. However, for old tapes the $0.5 \mathrm{~cm}$ mean stretch appears both statistically and clinically significant. Currently there is no advice on when the tape should be replaced. Our study was not designed to address this question, but we suggest replacement at regular intervals

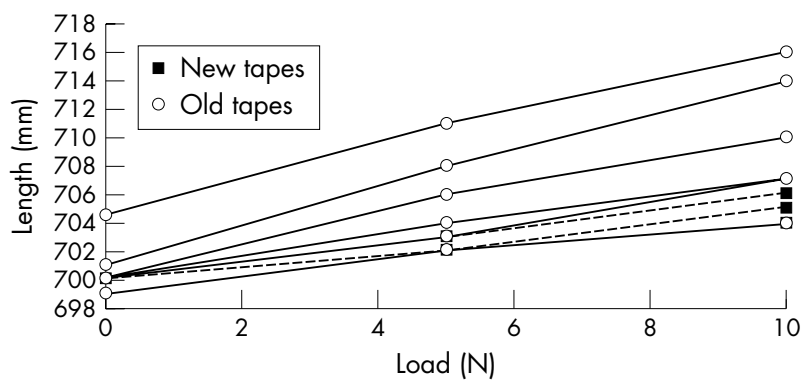

Figure 1 Comparison of the extension of old and new Lasso-o head circumference tape measures under a tensile load. Area 2-6 $\mathrm{N}$ load represents area of approximate force needed to pull the tape taught during a clinical measurement. 
and especially when the tape looks "used", as these tapes are often unreliable.

In statistical terms the intra- and inter-observer differences were both small. As reported in studies using other tapes, ${ }^{5}$ the intra-observer differences were smaller than inter-observer ones, giving weight to the recommendation that repeated measurements should ideally be carried out by the same observer. Despite this the reliability of both was very high. Nonetheless the larger variability in $9 \%$, especially if compounded by stretch in older tapes, could result in clinically significant differences in measurements in an important minority of children. This supports the recommendation that those responsible for measuring should be taught the appropriate method ${ }^{6}$ for the growth chart used and that everyone should use the same method.

\section{Authors' affiliations \\ J L Bartram, P S Baxter, Sheffield Children's Hospital, UK \\ A S Rigby, Academic Cardiology, University of Hull, UK}

Competing interests: none declared

Correspondence to: Dr J L Bartram, Sheffield Children's Hospital, Western Bank, Sheffield S10 2TH, UK; jacklbartram@hotmail.com

Accepted 15 November 2004

\section{REFERENCES}

1 Bhushan V, Paneth $N$. The reliability of neonatal head circumference measurement. J Clin Epidemiol 1991;44:1027-35.

2 Cameron N. The measurement of human growth. London: Croom Helm, 1984.

3 Bland JM, Altman DG. Statistical methods for assessing agreement between two methods of clinical measurement. Lancet 1986;i:307-10.

4 Donmall MC. Anthropometric and blood pressure studies in children from Shetland: reliability of measurement and the use of height-weight indices. Acta Paediatr Scand Suppl 1985;318:23-35.

5 Johnson TS, Engstrom JL, Gelhar DK. Intra- and interexaminer reliability of anthropometric measurements of term infants. J Pediatr Gastroenterol Nutr 1997;24:497-505.

6 Child Growth Foundation. Girls and boys head circumference chart. Child Growth Foundation, 1996.

\section{Gastrostomy feeding of children with cerebral palsy and carers' quality of life}

$\mathrm{T}$ he parents of children with severe cerebral palsy often worry about their child's nutrition and general health. Feeding through a gastrostomy tube may improve the child's nutrition and make life easier for the parents. Even though some are at first resistant to, or afraid of, the idea few parents regret agreeing to a gastrostomy. Now research in Oxford, Manchester, and Watford (Peter B Sulivan and colleagues. Developmental Medicine and Child Neurology 2004;46;796-800) has shown that there are significant improvements in the quality of life of carers after beginning gastrostomy tube feeding. The study included the main carers of 57 children who were severely disabled ( 53 unable to use their hands to feed themselves, 50 unable to sit independently) with cerebral palsy (43 with spastic quadriplegia). The children's mean age was 4 years and 4 months (range 5 months to 17 years) and 44 of the carers were the child's mother (four fathers, two grandmothers, and seven foster parents). The children all had their medical care provided by specialist multidisciplinary teams and the domestic carers were recruited to the study after the children had been referred to a paediatric surgeon for gastrostomy tube implacement. Quality of life was measured, using the UK Short-Form 36 version II (SF-36 II), at baseline (before gastrostomy), at 6 months, and at 12 months. Over the first 6 months there were substantial improvements in SF-36 II scores for mental health, role limitations due to emotional problems, physical functioning, social functioning, and energy/vitality. Between 6 and 12 months there were further improvements in mental health, social functioning, and energy/vitality scores. Although most carers improved, some did not and at 12 months one third of respondents had worse scores for energy/vitality, and a quarter for social functioning, compared with baseline. For most domains of the SF-36 II carers had significantly worse scores than a normal population at baseline but by 12 months their scores were not significantly different from the population norm (only the scores for role limitations due to emotional problems remained significantly worse than in the general population at 12 months). There were significant improvements in daily duration of feeding times (from 2.5 hours to 1 hour), ease of drug administration, and parental concerns over nutritional status.

For the carers of children with severe cerebral palsy and feeding difficulties gastrostomy tube feeding may result in significant improvements in quality of life. 